\title{
CAFÉ TORRADO E MOÍDO EM EMBALAGENS INERTIZADAS ${ }^{1}$
}

\author{
Rosa M. Vercelino ALVES ${ }^{\star}$, Emília E. MORI ${ }^{3}$, Cibele R. MILANEZ ${ }^{4}$, Marisa PADULA ${ }^{2}$
}

\section{RESUMO}

Avaliou-se o efeito das propriedades de barreira de materiais de embalagem e das condições do enchimento em equipamento flow pack vertical (com e sem injeção de nitrogênio), sobre a vida-útil de café torrado e moído. Avaliou-se três tipos de materiais de embalagem de estrutura composta de um laminado de poliéster metalizado (PETmet) e polietileno de baixa densidade linear (PEBDL) que diferiam na camada de metalização $\left(\mathrm{TPO}_{2}\right.$ de 0,$5 ; 2,9$ e $5,5 \mathrm{~cm}^{3}(\mathrm{CNTP}) / \mathrm{m}^{2} /$ dia a $25^{\circ} \mathrm{C}$, a seco e $\left.1 \mathrm{~atm}\right)$. Após formação, enchimento e termossoldagem das embalagens, as amostras foram estocadas a $25 \pm 2{ }^{\circ} \mathrm{C} / 65 \pm 3 \%$ UR. Durante a estocagem observou-se redução na concentração de oxigênio residual do espaço-livre das embalagens devido ao consumo em reações de oxidação, o que causou alterações sensoriais no produto e limitou sua vida-útil. Os resultados obtidos sugerem vida-útil para o café de, no mínimo, 6 meses a $25^{\circ} \mathrm{C} / 65^{\circ} \mathrm{UR}$ em embalagens inertizadas ( 2 a $3 \%$ de $\mathrm{O}_{2}$ residual em um espaço-livre de, em média, $680 \mathrm{~mL}$ a $25^{\circ} \mathrm{C}$ e $0,92 \mathrm{~atm}$ ), enquanto no sistema sem injeção de nitrogênio a vida-útil foi de 3 meses. Também verificou-se que materiais de embalagem com taxas de permeabilidade ao oxigênio próximas aos dos materiais avaliados não diferem no nivel de proteção oferecida a café torrado e moído até 6 meses de estocagem em embalagem inertizada.

Palavras-chave: café torrado e moído; embalagem inertizada; vida-útil.

\section{SUMMARY}

ROASTED AND GROUND COFFEE IN NITROGEN GAS FLUSHING PACKAGES. In this paper it was evaluated the effect of the barrier properties of packaging materials and filling conditions in vertical flow pack equipment (without and with nitrogen injection), on the shelf-life of roasted and ground coffee. Three types of packaging materials made by s laminate of metallized polyester (PETmet) and

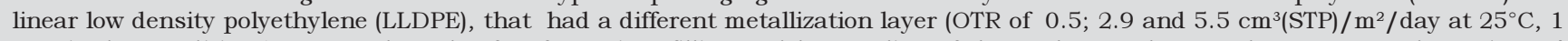
$\mathrm{atm}$ in dry conditions) were evaluated. After formation, filling and heatsealing of the packages, the samples were stored at $25 \pm 2{ }^{\circ} \mathrm{C} /$ $65 \pm 3 \% \mathrm{RH}$. A decrease of the residual oxygen concentration of the headspace was observed during the storage, probably caused by consumption of that gas in oxidation reactions. It caused sensorial changes in the product and limited its shelf-life. The results indicated that the shelf-life to the coffee was at least 6 months at $25^{\circ} \mathrm{C} / 65 \% \mathrm{RH}$ in nitrogen gas flushing packages $(2$ to $3 \%$ of residual oxygen in a headspace average of $680 \mathrm{~mL}$ at $25^{\circ} \mathrm{C}$ and $0.92 \mathrm{~atm}$ ), while in the system without nitrogen injection the shelf-life was 3 months. It was observed that packaging materials with oxygen transmission rates closer to the tested ones offer the same protection to roasted and ground coffee until 6 months of storage in nitrogen gas flushing packages.

Keywords: roasted and ground coffee; nitrogen gas flushing package; shelf-life.

\section{1- INTRODUÇÃO}

Café torrado e moído é susceptivel à perda de qualidade pela exposição ao oxigênio e umidade e pela estocagem a temperaturas elevadas. A oxidação das substâncias responsáveis pelo aroma e sabor e a oxidação de lipídeos contidos no café levam à perda do sabor e odor característicos e ao desenvolvimento do sabor de ranço, resultando no que é denominado de "café velho". A umidade, além de acelerar o processo de deterioração do café, pode ocasionar, a partir de um determinado teor, aglomeração e posteriormente o desenvolvimento microbiano $[2,5,10]$.

Também são esperadas diferenças na qualidade do café dependendo do grau de torrefação, granulometria e características do grão tais como: variedade, número de defeitos, etc.

Outro fator importante é a liberação de $\mathrm{CO}_{2}$ devido ao processo de torrefação do café. Este gás é liberado

1. Recebido para publicação em 30/04/2001. Aceito para publicação em 10/07/2002 (000627).

2 ITAL-CETEA. Caixa Postal 139, CEP 13073-001, SP,

${ }^{3}$ LAFISE-CETEA.

${ }^{4}$ FAPESP

* A quem a correspondência deve ser enviada. rapidamente após as primeiras 24 horas da moagem dos grãos [10].

Desta forma, café torrado e moído com qualidade requer sistemas de embalagem que o protejam do oxigênio e da umidade, de forma a preservar, e por maior tempo, a qualidade inicial.

Para café torrado e moído existem quatro sistemas de acondicionamento que são:

- Em atmosfera normal

- Pela redução do teor do oxigênio utilizando vácuo

- Pela redução do teor de oxigênio através da substituição do ar atmosférico do espaço-livre por nitrogênio

- Pela redução do teor de oxigênio através do uso de absorvedores de oxigênio

O sistema com atmosfera normal é amplamente utilizado no Brasil e consiste no acondicionamento do produto na embalagem logo após os processos de torrefação e moagem e, em seguida, a embalagem é furada para evitar o estufamento devido a liberação de $\mathrm{CO}_{2}$. O mercado utiliza como material de embalagem, principalmente a estrutura laminada composta de PET/impressão/metalização/PEBD e denomina a embalagem de almofada. Neste sistema a vida-útil do café torrado e moído des- 
crita na literatura é cerca de 10 a 20 dias [2, 10], enquanto o mercado brasileiro declara validade de 90 dias.

$\mathrm{O}$ sistema de embalagem à vácuo foi introduzido no

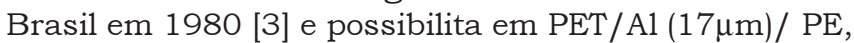
uma vida-útil de 350 dias a $23^{\circ} \mathrm{C} / 65 \%$ UR [6]. Antes do acondicionamento à vácuo, o produto passa por uma etapa de desgaseificação (8 a 24 horas, dependendo do grau de torrefação e granulometria e este período deve ser o minimo possivel para minimizar a oxidação do produto. Às vezes, é adicionado uma quarta camada de náilon (PA) para aumentar a resistência mecânica da embalagem [10]. Uma desvantagem da embalagem à vácuo é a de formar um bloco rígido, o que requer o uso de uma embalagem secundária de cartão ou uma estrutura com laminação especial, onde o PET é unido ao conjunto apenas nas áreas de termossoldagens (double wall), para melhorar o aspecto visual da impressão, dispensando o cartucho. O período de vida-útil declarado para café torrado e moído a vácuo varia de 1 a 1,5 anos no mercado brasileiro.

O uso de embalagens flexiveis com gás inerte é uma terceira alternativa. Durante a formação da embalagem a retirada do oxigênio é feita em equipamento automático que promove a termossoldagem da embalagem e o ar do espaço-livre é substituído por nitrogênio por meio de um fluxo contínuo desse gás, que dilui o ar ao redor do produto, antes da embalagem ser termosselada (gas flushing) [11].

O material de embalagem usado é um laminado onde um dos componentes é metalizado (PET ou BOPP - polipropileno bi-orientado) que é o componente barreira da estrutura. Este sistema também requer um tempo de desgaseificação do café antes do acondicionamento na embalagem ou uso de válvulas "one-way" que são fixadas na embalagem. Essas válvulas permitem que o $\mathrm{CO}_{2}$ saia do interior da embalagem sem deixar que $\mathrm{O}_{2}$ do ambiente externo entre para dentro da embalagem [10, 13].

Segundo informe técnico [9] a vida-útil do café torrado e moído em embalagens com gás inerte é de 6 a 8 meses se o oxigênio residual for inferior a $1 \%$. JENKINS $\&$ HARRINGTON [4] citam que a vida-útil em embalagem PETmet/PE é de 3 meses $\left(\mathrm{O}_{2}\right.$ inicial < $\left.1 \%\right)$.

$\mathrm{E}$, finalmente, uma quarta forma de acondicionamento de café torrado e moído é utilizando "embalagens ativas", sendo mais comum o uso de um sistema para absorver o oxigênio. $\mathrm{O}$ absorvedor de oxigênio mais utilizado é na forma de sachets contendo agentes redutores à base de pós de ferro [12]. Outro sistema já estudado no Brasil para café torrado e moído é o que utiliza sistemas enzimáticos (glicose/ oxidase/ catalase) incorporado ao produto para absorver o oxigênio [1]. Também existe no Japão, absorvedores de gás carbônico e oxigênio que poderiam ser avaliados para café torrado e moído [12].

O café torrado e moído no Brasil é comercializado em sua maioria, em embalagens almofadas e em embalagens à vácuo. Considerando os custos de materiais de embalagem flexiveis e equipamentos utilizados para café torrado e moído verifica-se que o custo do sistema de acondicionamento à vácuo é muito superior ao do sistema almofada. Desta forma, quando se procura diversificação, pode ser inviável para empresas de menor porte adotar um sistema de acondicionamento à vácuo. Mas, por outro lado, é inegável que o sistema à vácuo possibilita melhor preservação da qualidade inicial do produto e conseqüentemente maior vida-útil.

Entretanto, uma alternativa à embalagem tipo almofada é a tecnologia de embalagens flexiveis inertizadas. Mas, os custos associados a essa tecnologia envolvem além do equipamento flow pack vertical, a instalação de um sistema de injeção de nitrogênio, além do próprio custo do gás. Este sistema também requer um monitoramento do residual de oxigênio no espaço-livre da embalagem utilizando equipamentos analisadores de gás, ou dispositivos instalados no equipamento, que impede seu funcionamento caso o teor de oxigênio ultrapasse um limite pré-fixado.

O acondicionamento de café torrado e moído em embalagens inertizadas requer o controle do oxigênio no espaço-livre da embalagem em niveis baixos, de forma a permitir uma melhor preservação da qualidade inicial do produto e conseqüentemente maior vida-útil. Há que se lembrar que este sistema de acondicionamento requer um tempo de descanso para que parte do $\mathrm{CO}_{2}$ seja eliminado.

O estudo do sistema de acondicionamento com inertização, objeto deste trabalho, é portanto uma alternativa intermediária entre os sistemas à vácuo e o almofada tradicional, pois requer menor investimento inicial (equipamentos) e de material de embalagem que o sistema à vácuo, ao mesmo tempo que permite preservar a qualidade do produto por mais tempo, oferecendo ao consumidor um produto melhor e com maior vida-útil que as embalagens tipo almofada.

Assim, neste trabalho estudou-se os sistemas de acondicionamento com e sem inertização para obtenção de dados sobre o efeito das propriedades de barreira dos materiais de embalagem testados e o efeito do teor de oxigênio residual do espaço-livre, na vida-útil do café torrado e moído.

\section{2 - MATERIAL E MÉTODOS}

\section{1 - Embalagens}

As estruturas laminadas selecionadas foram identificadas como descrito a seguir e apresentavam as características contidas na Tabela 1.

- Barreira: Impressão externa/Poliéster (PET)metalizado alta barreira/Polietileno de baixa densidade linear (PEBDL);

- Intermediāria: Impressão externa/PET-metalizado/ PEBDL;

- Normal: PET/impressão/metalização/PEBDL;

- Padrão: PET/Alumínio (A1)/Polietileno de baixa densidade (PEBD), com envoltório externo de PET. 
As embalagens inertizadas apresentavam dimensões de $16 \times 29 \mathrm{~cm}$, três termossoldagens sendo duas transversais e uma longitudinal e continham, em média, 500g (variando de $480 \mathrm{~g}$ a $520 \mathrm{~g}$ ) de café torrado e moído.

TABELA 1. Características dos materiais de embalagem.

\begin{tabular}{|c|c|c|c|c|c|c|}
\hline \multirow[t]{3}{*}{ Parâmetros } & & \multicolumn{5}{|c|}{ Materiais de embalagem } \\
\hline & & \multicolumn{2}{|c|}{ Barreira } & \multirow[t]{2}{*}{ Intermediária } & \multirow[t]{2}{*}{ Normal } & \multirow[t]{2}{*}{ Padrão } \\
\hline & & $1^{\circ}$ Estudo & $2^{\circ}$ Estudo & & & \\
\hline Espessura total & M & $71^{1}$ & $68^{6}$ & $68^{1}$ & $64^{1}$ & $124^{1}$ \\
\hline$(\mu \mathrm{m})$ & IV & $69-73$ & $64-72$ & $63-71$ & $62-67$ & $118-130$ \\
\hline Espessura parcial & M & $13 / 55^{1}$ & $13 / 50^{5}$ & $13 / 52^{1}$ & $13 / 51^{1}$ & $13 / 8 / 100^{1}$ \\
\hline \multirow[t]{3}{*}{$(\mu \mathrm{m})$} & IV & $11-16 / 52-$ & $11-14 / 47-$ & $12-14 / 49-54$ & $11-15 / 48-$ & $11-14 /^{*} / 96-$ \\
\hline & & 59 & 55 & & 54 & 105 \\
\hline & M & $0,50^{2}$ & $0,57^{3}$ & $2,86^{2}$ & $5,5^{2}$ & $0,65^{3}$ \\
\hline $\mathrm{TPO}_{2}$ & IV & $0,27-1,10$ & $0,38-0,87$ & $2,51-3,53$ & $2,61-7,58$ & $0,58-0,71$ \\
\hline \multicolumn{7}{|l|}{$\left(\mathrm{cm}^{3}(\mathrm{CNTP}) / \mathrm{m}^{2} / \mathrm{dia}\right)^{\star \star}$} \\
\hline & M & $0,80^{4}$ & $1,13^{4}$ & $0,82^{4}$ & $1,05^{2}$ & $<0,01^{4}$ \\
\hline $\begin{array}{c}\text { TPVA }(\mathrm{g} \\
\left.\text { água } / \mathrm{m}^{2} / \mathrm{dia}\right)^{\star \star \star}\end{array}$ & IV & $0,56-0,98$ & $0,76-1,45$ & $0,69-0,98$ & $0,72-1,24$ & - \\
\hline
\end{tabular}

Média referente a $\left({ }^{1}\right)$ vinte e cinco, $\left({ }^{2}\right)$ seis, $\left({ }^{3}\right)$ três, $\left({ }^{4}\right)$ quatro, $\left({ }^{5}\right)$ dez e $\left(^{6}\right)$ vinte repetiIVões

* - obtido por diferença, ** $25^{\circ} \mathrm{C}$, a seco e $1 \mathrm{~atm},{ }^{* * *} 38^{\circ} \mathrm{C} / 90 \% \mathrm{UR}$

\section{2 - Produto}

No primeiro estudo o café torrado e moído apresentava ponto de torra médio, moagem fina e umidade inicial de $2,23 \%$ b.s. (1,94 a 2,34\% b.s.). No segundo estudo o café apresentava ponto de torra médio, moagem média e umidade inicial de $3,00 \%$ b.s. $(2,87$ a $4,30 \%$ b.s.).

\section{3 - Estudo da estabilidade}

No primeiro estudo o acondicionamento do café torrado e moído nos três tipos de materiais de embalagem metalizados (Tabela 1) foi feito em equipamento flow pack com injeção de nitrogênio (gas flushing). O nitrogênio utilizado no equipamento era gerado por um sistema de membrana. Para uso como padrão, foi acondicionado café do mesmo lote em embalagem a vácuo (estrutura padrão, Tabela 1), em máquina de marca Open.

No segundo estudo o café torrado e moído foi acondicionado apenas no material metalizado barreira, em equipamento flow pack sem e com injeção de nitrogênio. Parte do produto com nitrogênio foi separado como padrão para testes sensoriais.

Os produtos foram estocados a $25 \pm 2{ }^{\circ} \mathrm{C} / 65 \pm 3 \% \mathrm{UR}$, exceto os padrões, que foram estocados a $-18 \pm 1^{\circ} \mathrm{C}$. Periodicamente, as embalagens inertizadas foram avaliadas quanto à composição gasosa e volume do espaçolivre, bem como a integridade das termossoldagens. O café torrado e moído foi avaliado quanto à qualidade sensorial. As metodologias utilizadas são descritas a seguir.

\section{- Composição gasosa do espaço livre}

No primeiro estudo, a determinação da composição gasosa do interior das embalagens foi feita através da coleta de aliquotas de gás do espaço-livre, através de um septo, com seringa hermética e posterior quantificação em cromatógrafo a gás Shimadzu, modelo 14 A, operando com detector de condutividade térmica a $150^{\circ} \mathrm{C}$, colunas (Peneira molecular $13 \mathrm{X}$ e Porapak N) a $50^{\circ} \mathrm{C}$ e injetor a $70^{\circ} \mathrm{C}$. Os resultados de cromatografia foram analisados por um integrador Shimadzu, modelo CR4A, com base em curvas padrões feitas com gases de calibração [7].

No segundo estudo, a composição gasosa do espaço-livre das embalagens foi quantificada em analisador PBI Dansensor, modelo Combi Check 9800-1, através da coleta dos gases do espaço-livre por um septo de silicone.

\section{- Volume do espaço livre}

O volume total de gases do espaço-livre foi lido diretamente quando as embalagens foram abertas dentro de um recipiente com água e o gás do espaço-livre foi coletado com o auxílio de um funil, em um proveta graduada, invertida sobre o funil, que permitiu a leitura direta do volume de gás, à temperatura de $25^{\circ} \mathrm{C}$ e pressão atmosférica local de 0,92atm [7].

\section{- Integridade da termossoldagem}

Avaliou-se a termossoldagem aplicando com o auxílio de pipeta Pasteur, pequena quantidade de uma solução colorida de baixa tensão superficial $(0,5 \%$ Rhodamina B em isopropanol), em toda a parte interna das regiões de termossoldagem [7]. Após 15 minutos, era retirado com o auxílio da pipeta o excesso de solução e a embalagem era seca em estufa. Em seguida abria-se cuidadosamente a termossoldagem procurando detectar regiões com penetração da solução.

\section{- Análise sensorial}

O café torrado e moído foi avaliado sensorialmente quanto ao envelhecimento em relação ao produto padrão congelado $(0$ = nenhum e 9 = inaceitável $)$ através de uma escala de categoria não-estruturada de $10 \mathrm{~cm}$. O limite aceitável de envelhecimento foi considerado quando o produto fosse classificado com o ponto 3,5 .

\section{3 - RESULTADOS E DISCUSSÃO}

\section{1 - Efeito das diferentes propriedades de barreira dos materiais no $1^{\circ}$ estudo}

\subsection{1 - Volume do espaço-livre}

O volume total de gases do espaço-livre foi quantificado a partir do $7^{\circ}$ aos 91 dias de estocagem (7 perídos, 4 embalagens de cada material por periodo) e não verificou-se evolução de espaço-livre. Entretanto, nas unidades de um mesmo tipo de material de embalagem, observou-se grandes variações no volume total de gases. Foram quantificados volumes de gases individuais de 500 a $850 \mathrm{~mL}\left(\mathrm{a} 25^{\circ} \mathrm{C}\right.$ e $\left.0,92 \mathrm{~atm}\right)$, mas, de ma- 
neira geral, as embalagens de estrutura intermediária foram as que apresentaram menor volume (média de $642 \mathrm{~mL}$, variando de 500 a $750 \mathrm{~mL}$ ); as de estrutura normal os maiores volumes (média de $711 \mathrm{~mL}$, variando de 550 a $850 \mathrm{~mL}$ ) e a de estrutura barreira apresentaram volumes intermediários entre os dos outros materiais (média de $668 \mathrm{~mL}$, variando de 550 a $830 \mathrm{~mL}$ ).

Provavelmente o volume total de gases é devido à liberação de $\mathrm{CO}_{2}$, que pode ter sido excessiva, o que indica que o tempo de descanso de $2 \mathrm{~h}$ entre a moagem e o acondicionamento na embalagem utilizado no estudo não foi suficiente. A literatura recomenda tempos de 2 a 24 horas dependendo da granulometria e ponto de torra do café $[2,8]$.

\subsection{2 - Composição gasosa do espaço-livre}

Imediatamente após acondicionamento, foram feitas análises da concentração de $\mathrm{O}_{2}$ no analisador, que indicaram que o primeiro material a acondicionar o produto (estrutura intermediária) apresentava teor inicial de $\mathrm{O}_{2}$ de $2 \%(2,1-2,2 \%)$, e de $1,8 \%(1,7-1,9 \%)$ e $1,4 \%$, respectivamente nos materiais da estrutura barreira e da estrutura normal.

Esses niveis residuais de $\mathrm{O}_{2}$ são, em parte, resultantes do sistema utilizado para gerar nitrogênio na empresa em que foi feito o acondicionamento do produto, que é através de membranas (hoje sendo utilizado no máximo da vazão permissivel, o que aumenta a presença de oxigênio). Outro problema é a existência de poucos pontos de injeção de gás nitrogênio na máquina de acondicionamento do produto. Esses resultados não foram plotados no gráfico da evolução da concentração de oxigênio, que será apresentado a seguir, por se tratar de equipamento e método diferenciados do usado ao longo da estocagem.

Os teores de oxigênio residual inicial talvez sejam excessivos se considerarmos o grande volume de espaço-livre das embalagens.

Pela Figura 1, observa-se que após 1 dia de estocagem, o teor de oxigênio dos três tipos de embalagem era inferior a $2 \%$.

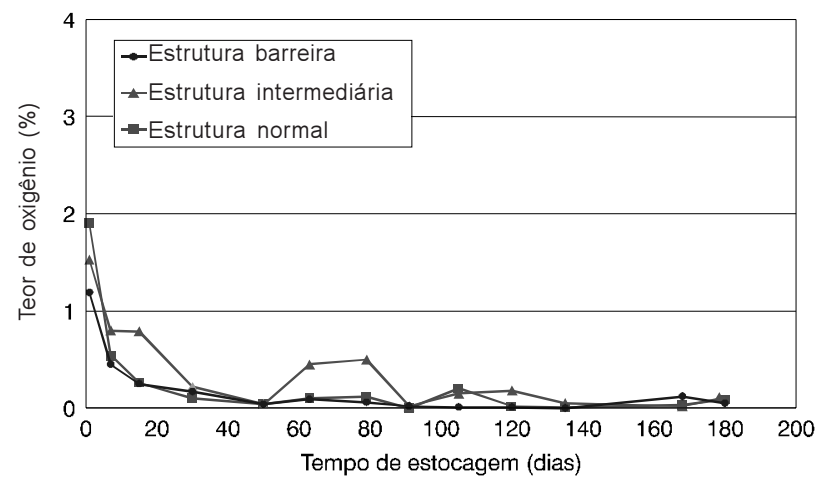

FIGURA 1. Concentração de oxigênio (\%v/v) no espaço-livre das embalagens, durante a estocagem.
Ao longo da estocagem observou-se uma redução da concentração de oxigênio devido ao seu consumo em reações de oxidação. A literatura cita que isto deve ocorrer em 3 a 6 semanas, dependendo do teor de oxigênio residual [2].

Nas análises efetuadas nas embalagens ao longo da estocagem a $25^{\circ} \mathrm{C}$, foram quantificados maiores teores de $\mathrm{O}_{2}$ no espaço-livre nas de estrutura intermediária (principalmente aos 7, 15, 63 e 79 dias). Como este material apresentou uma $\mathrm{TPO}_{2}$ intermediária entre os outros dois materiais em estudo, esses teores de $\mathrm{O}_{2}$ devem ser provenientes do maior teor de $\mathrm{O}_{2}$ residual quando do acondicionamento do produto.

Foram observadas variações nos teores de $\mathrm{CO}_{2}$ do espaço-livre das embalagens com os três tipos de materiais ao longo da estocagem a $25^{\circ} \mathrm{C}$. Em média, esses teores variaram entre $4,5 \%$ a $11,9 \%$ (estrutura barreira), 3,3\% a 14,2\% (estrutura intermediária) e 2,9\% a $10,0 \%$ (estrutura normal). Como as faixas são semelhantes e não houve tendência de perda de $\mathrm{CO}_{2}$ ao longo da estocagem, observa-se que os três materiais ofereceram barreira ao $\mathrm{CO}_{2}$ semelhantes para o café torrado e moído, nas condições de estudo.

Os teores de $\mathrm{N}_{2}$ oscilaram, em média, de $85,1 \%$ a $92,4 \%$ (estrutura barreira), 82,9 a 95,2\% (estrutura intermediária) e de 82,0 a 94,5\% (estrutura normal), contrabalançando as oscilações nas porcentagens de $\mathrm{CO}_{2}$.

Nas embalagens em que foram feitas as quantificações de volume total de gases do espaço-livre, calculou-se os volumes de oxigênio presente, considerando as concentrações desse gás determinadas nas análises de composição gasosa

Observou-se que, aos 7 dias de estocagem havia, em média, 3 a $4 \mathrm{~mL}$ de oxigênio/500g de café. Este volume de oxigênio inicialmente deveria ser maior considerando que parte do oxigênio foi rapidamente consumido nas reações de oxidação do produto. Ao longo da estocagem observou-se maiores volumes de $\mathrm{O}_{2}$ na embalagem de estrutura intermediária.

A literatura cita que $30 \mathrm{~cm}^{3}$ de oxigênio/ $1 \mathrm{~kg}$ café já é suficiente para deteriorá-lo [2].

\subsection{3 - Integridade da termossoldagem}

As avaliações feitas nas embalagens flexiveis fabricadas com estrutura barreira (36 unidades), estrutura intermediária (38 unidades) e estrutura normal (37 unidades) não apresentaram penetração da solução colorida, o que indica que as embalagens apresentavam termossoldagens integras.

\subsection{4 - Avaliação sensorial}

Observa-se pela Figura 2, que durante os 180 dias de estocagem apenas o café torrado e moído acondicionado na estrutura intermediária apresentou tendência linear de envelhecimento em função do tempo de estocagem.

Foi feita uma reta de regressão, estimada a partir dos dados da análise sensorial do envelhecimento do 
café acondicionado na estrutura intermediária. A equação de reta obtida foi $\mathrm{EV}=1,4273+0,01215$ x DIAS, com coeficiente de ajuste de $76 \%$. O intervalo de tempo para atingir o ponto 3,5 na escala de envelhecimento, quando se atingiu o limite de aceitabilidade, foi aos 170 dias de estocagem, com intervalo de 130 a 260 dias.

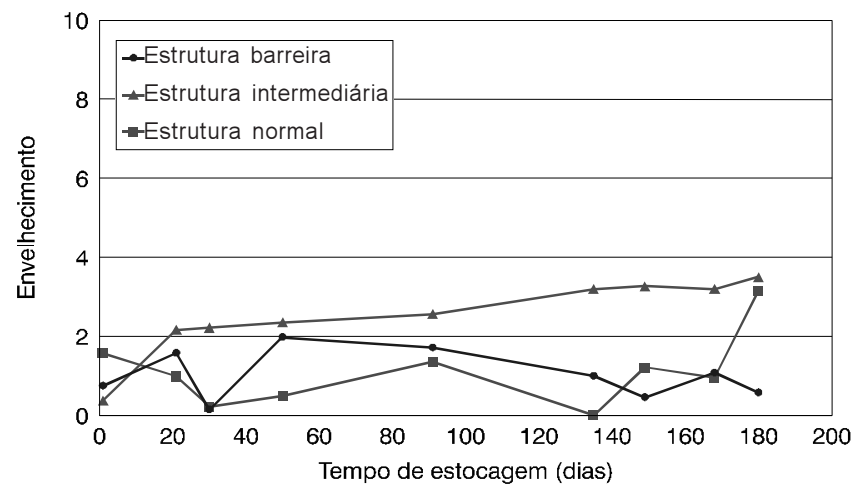

FIGURA 2. Envelhecimento do café torrado e moído, nos diversos materiais de embalagem, ao longo da estocagem, a $25^{\circ} \mathrm{C} / 65 \% \mathrm{UR}$.

Para as demais embalagens, não houve tendência linear de envelhecimento do café em função do tempo e as estimativas de vida-de-prateleira não puderam ser determinadas (baixos valores de coeficientes de ajuste $\left.\mathrm{R}^{2}\right)$. Até os 180 dias de estocagem a $25^{\circ} \mathrm{C} / 65 \% \mathrm{UR}$ as amostras de café torrado e moído acondicionadas nas estruturas barreira e normal mantiveram-se aceitáveis para consumo.

Como a estrutura intermediária apresenta uma $\mathrm{TPO}_{2}$ intermediária entre os outros dois materiais e como todas as embalagens apresentaram termossoldagens herméticas, conclui-se que a causa da maior deterioração do café nesta estrutura foram os maiores teores de $\mathrm{O}_{2}$ observados no espaço-livre das embalagens desse material.

$\mathrm{O}$ café acondicionado na estrutura barreira $\left(\mathrm{TPO}_{2}=0,5 \mathrm{~cm}^{3}\right.$ (CNTP) $/ \mathrm{m}^{2}$.dia) e na normal $\left(\mathrm{TPO}_{2}=5,5 \mathrm{~cm}^{3}(\mathrm{CNTP}) / \mathrm{m}^{2}\right.$.dia $)$ praticamente não diferiram porque provavelmente essas embalagens apresentavam uma quantidade de oxigênio no espaço-livre já suficiente para deteriorar a qualidade do produto ao longo da estocagem e assim não foi percebida diferença de proteção entre os materiais testados, até 180 dias de estocagem a $25^{\circ} \mathrm{C} / 65 \% \mathrm{UR}$.

\section{2 - Efeito de diferentes condições de acondicio- namento no equipamento no 2 o estudo}

\subsection{1 - Volume do espaço-livre}

O volume total de gases do espaço-livre das embalagens (a $25^{\circ} \mathrm{C}$ e $\left.0,92 \mathrm{~atm}\right)$, média de seis repetições, foi quantificado após 8 e 100 dias do acondicionamento do produto na embalagem. Aos 8 dias, os valores encontrados foram de 613mL (570-650mL) e 687mL (620-710mL), respectivamente para enchimento sem e com nitrogênio. E aos 100 dias, os valores foram de $502 \mathrm{~mL}$ (430-
$630 \mathrm{~mL})$ e $724 \mathrm{~mL}(710-750 \mathrm{~mL})$, respectivamente para enchimento sem e com nitrogênio.

As embalagens com $\mathrm{N}_{2}$ mantiveram o volume total de gases do espaço-livre durante a estocagem a $25^{\circ} \mathrm{C}$ devido às barreiras a gases oferecidas pelo material da embalagem. Entretanto, as embalagens sem $\mathrm{N}_{2}$ demonstraram certa diminuição no volume total, que, provavelmente, decorreu do consumo de $\mathrm{O}_{2}$ pelo produto.

\subsection{2 - Composição gasosa do espaço-livre}

Imediatamente após o acondicionamento, foram feitas análises da concentração de $\mathrm{O}_{2}$ do espaço-livre com o analisador, e os resultados obtidos (média referente a três embalagens) foram de $11,9 \%(8,4$ a $13,8 \%)$ nas embalagens sem $\mathrm{N}_{2}$ e 3,3\% (3,3 a 3,3\%) nas embalagens $\operatorname{com~} \mathrm{N}_{2}$. Devido ầ liberação de $\mathrm{CO}_{2}$ pelo produto, o nível de $\mathrm{O}_{2}$ foi reduzido de $21 \%$ (teor de oxigênio do ar) para $11 \%$ nas embalagens sem nitrogênio.

Observou-se que o oxigênio residual foi totalmente consumido na embalagem com injeção de nitrogênio após 5 dias do acondicionamento do produto na embalagem. $\mathrm{Na}$ embalagem sem $\mathrm{N}_{2}$ o consumo de $\mathrm{O}_{2}$ também foi rápido, sendo este totalmente consumido após 40 dias de estocagem a $25^{\circ} \mathrm{C} / 65 \% \mathrm{UR}$.

Da mesma forma como comentado anteriormente, os teores de oxigênio residual nas embalagens com $\mathrm{N}_{2}$ são excessivos ao se considerar o volume do espaço-livre das embalagens.

Os teores de $\mathrm{CO}_{2}$ do espaço-livre das embalagens variaram em média entre 15,9 e 20,8\% e entre 6,5 e 8,0\%, respectivamente nas embalagens sem e com $\mathrm{N}_{2}$. Não se observou tendência de perda de $\mathrm{CO}_{2}$ ao longo da estocagem indicando que o material de embalagem utilizado oferece boa barreira a esse gás.

Em média, os teores de $\mathrm{N}_{2}$ oscilaram entre 78,7 a $86,0 \%$ e entre 92,0 e 93,5\%, respectivamente nas embalagens sem e com nitrogênio. Os teores de $\mathrm{N}_{2}$ medidos contrabalançaram as oscilações nas porcentagens dos outros gases, e principalmente aumentou (em porcentagem) ao longo da estocagem devido ao consumo de $\mathrm{O}_{2}$ pelo produto.

\subsection{3 - Integridade da termossoldagem}

Nas avaliações feitas nas embalagens acondicionadas sem $\mathrm{N}_{2}$ (40 unidades) e com $\mathrm{N}_{2}$ (48 unidades) não se observou penetração de solução colorida nas termossoldagens, o que indica que as embalagens apresentavam termossoldagens integras.

\subsection{4 - Avaliação sensorial}

A Figura 3 apresenta os resultados da avaliação sensorial do café torrado e moído ao longo da estocagem.

Foram feitos gráficos de regressão estimados a partir dos dados da análise sensorial do envelhecimento do café acondicionado na estrutura barreira, acondicionados com e sem injeção de nitrogênio.

A equação da reta para o envelhecimento da amostra sem $\mathrm{N}_{2}$ é: $\mathrm{EV}=1,550+0,021$ X DIAS, com coeficiente 
de ajuste de $62 \%$. O intervalo de tempo para atingir o limite de aceitabilidade (ponto 3,5 ) na escala de envelhecimento (0 - nenhum a 9 - muito velho) foi de 91 dias de estocagem com coeficiente de variação de 50 a 194 dias. O intervalo de confiança apresentou faixa maior devido aos pontos médios das épocas estarem muito dispersos.

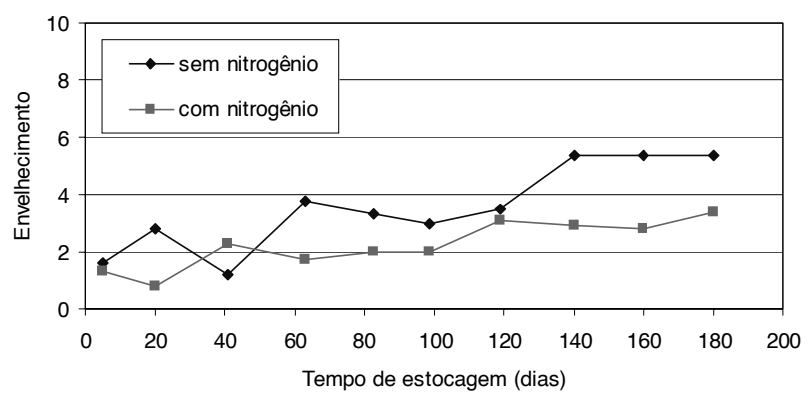

FIGURA 3. Envelhecimento do café torrado e moído, acondicionado com e sem $\mathrm{N}_{2}$, ao longo da estocagem, a $25^{\circ} \mathrm{C} /$ $65 \%$ UR.

A equação da reta para o envelhecimento da amostra com $\mathrm{N}_{2}$ é: $\mathrm{EV}=1,092+0,022$ X DIAS, com coeficiente de ajuste de $79 \%$. O intervalo de tempo para atingir o limite de aceitabilidade (ponto 3,5) foi de 190 dias de estocagem, com coeficiente de variação de 155 a 260 dias.

Pelos resultados apresentados, tem-se que o processo de acondicionamento com $\mathrm{N}_{2}$ aumenta a vida-útil em comparação ao sistema sem injeção de $\mathrm{N}_{2}$, com materiais de embalagem com taxas de permeabilidade ao oxigênio próximas de $0,5 \mathrm{~cm}^{3}(\mathrm{CNTP}) / \mathrm{m}^{2} /$ dia.

Pelos resultados obtidos no primeiro e segundo estudos, observa-se que a utilização de embalagens inertizadas pode prolongar a vida-útil de café torrado e moído para períodos de 6 meses a $25^{\circ} \mathrm{C} / 65 \%$ UR.

\section{4 - CONCLUSÕES}

Com base nos resultados obtidos nos dois estudos conclui-se que:

- O processo de acondicionamento de café torrado e moído em embalagens com atmosfera modificada (inertização com $\mathrm{N}_{2}$ ) leva a maiores periodos de vida-útil em comparação ao sistema sem injeção de $\mathrm{N}_{2}$.

- Materiais de embalagem com taxas de permeabilidade ao oxigênio na faixa de 0,5 a $5,5 \mathrm{~cm}^{3}(\mathrm{CNTP}) /$ $\mathrm{m}^{2} /$ dia não diferem no nivel de proteção oferecida ao café torrado e moído até 6 meses de estocagem se, o processo de acondicionamento (inertização com $\mathrm{N}_{2}$ ), levar a teores de oxigênio residual no espaço-livre nos niveis quantificados neste estudo.
- Nas condições do estudo, verificou-se que o período de vida-útil para o café torrado e moído em embalagem inertizada foi de, no mínimo, 6 meses a $25^{\circ} \mathrm{C} / 65 \% \mathrm{UR}$.

\section{5 - REFERÊNCIAS BIBLIOGRÁFICAS}

[1] ADELL, E. A A, MORETTI, R.H. Contribuição ao estudo de absorvedores enzimáticos de oxigênio na conservação de café torrado e moído. Campinas: 1995. 57p. Dissertação (Mestrado em Tecnologia de Alimentos). Faculdade de Engenharia de Alimentos da Universidade Estadual de Campinas (UNICAMP).

[2] CABRAL, A C.D., FERnANDES, M. H. C. Embalagem para café torrado e café torrado e moído. Boletim do ITAL, Campinas, v.19, n.1, p.1-19, 1982.

[3] DATAMARK Consultores. A indústria brasileira de embalagem. São Paulo, Datamark, 1997. p.139.

[4] JENkins W. A, HARRINGTON, J. P. Coffee. In: PACKAGING foods with plastics. Lancaster: Technomic Publishing Co. Inc., 1991. cap. 13, p. 189-195.

[5] LABUZA, T.P. Shelf-life of coffee and tea. In: SHELFlife dating of foods. Westport: Food \& Nutrition Press Inc, 1982. cap.16, p.359-372.

[6] MORI, E. E. M., FERREIRA, V. L. P., GUedes, L. B. R., ARDITO, E. F. G., YOTSUYANAGI, K., SOLER, R. M. Vidade-prateleira de café torrado e moído embalado a vácuo. Boletim do ITAL, Campinas, v.22, n.1, p.67-89, 1985.

[7] OliveirA, L. M., ALVES, R.M.V., SARANTÓPOUlOS, C.I.G.L., PADUlA, M., GARCIA, E.E.C., COLTRO, L. Ensaios para avaliação de embalagens plásticas flexíveis. Campinas: CETEA/ITAL, 1996. 202p.

[8] REINECCIUS, T. Roast \& ground coffee - Factors that influence and reflect loss in quality. St. Paul: Aspen Research Corporation, 1996. 23p.

[9] ROBERT BOSCH MÁquinas DE EMBAlagem. PROBLEMAS e soluções no empacotamento de café torrado e moído de forma a garantir-lhe uma longa vidade-prateleira. São Paulo: Bosch, 6p.1981.

[10] ROBERTSON, G.L. Packaging of beverages. In: FOOD packaging principles and practice. New York: Marcel Dekker, 1993. cap.19, p.588-621.

[11] SARANTÓPOUlOS, C. I. G. L., ALVES, R. M. V., OLIVEIRA, L. M., GOMES, T. C. Equipamentos para acondicionamento em atmosfera modificada. In.: EMBALAGENS com atmosfera modificada. Campinas: CETEA/ ITAL, 1996a. cap. 3, p. 33-42.

[12] SARANTÓPOUlOS, C. I. G. L., ALVES, R. M. V., OLIVEIRA, L. M., GOMES, T. C. Embalagens ativas. In.: EMBALAGENS com atmosfera modificada. Campinas: CETEA/ITAL, 1996b. cap. 7, p. 99-114.

[13] SUBRAMANIAM, P.J. Miscellaneous applications. In: PARRY, R.T. Principles and applications of modified atmosphere packaging of foods. Glasgow: Blackie Academic \& Professional Packaging of Foods, 1993. cap.8, p. 170-188.

\section{6 - AGRADECIMENTOS}

Ao Consórcio Brasileiro de Pesquisa e Desenvolvimento do Café, pelo apoio financeiro concedido. 